\title{
Variance Ratio Tests Of Random Walk Hypothesis Of The Euro Exchange Rate
}

\author{
Jeng-Hong Chen, Albany State University, USA
}

\begin{abstract}
The introduction of the Euro has drawn interested parties' attention on the Euro/U.S. Dollar exchange rate market. In this research, three variance ratio tests: Lo-MacKinlay's (1988) conventional variance ratio test, Chow-Denning's (1993) simple multiple variance ratio test, and Wright's (2000) non-parametric ranks and signs based variance ratio tests are adopted to test the random walk hypothesis $(R W H)$ of the Euro/U.S. Dollar exchange rate market using the data from January 1999 to July 2008. All of three variance ratio tests' results show that the RWH cannot be rejected. Therefore, the Euro/U.S. Dollar exchange rate market is regarded as weak-form efficient.
\end{abstract}

Keywords: Market Efficiency, Random Walk Hypothesis, Variance Ratio Tests, Euro Exchange Rate

\section{INTRODUCTION}

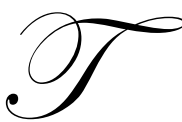

he efficient market hypothesis (EMH) states that the security price fully reflects all available information. The market is regarded as weak-form efficient if the current price of a security fully reflects all its information contained in its past prices, which means that studying the behaviors of historical prices cannot earn abnormal returns. The implication of weak-form efficiency is the random walk hypothesis (RWH), which indicates that successive price changes are random and serially independent.

Although there are an abundance of empirical studies concerning testing the RWH (Liu and He (1991), Huang (1995), Poshakwale (1996), Islam and Khaled (2005), etc.), the interest in the market efficiency still remains in academicians and practitioners. Academicians would like to better know the return patterns of financial assets. Practitioners attempt to identify the market inefficiency to develop global trading strategies. Today, the availability of new market data, the longer study period, and more methodologies satisfy academicians' and practitioners' interest.

Among methodologies available to test RWH, variance ratio tests are considered powerful RWH test methodologies. Lo and MacKinlay (1988) initiate the conventional variance ratio test. Later, Chow and Denning (1993) modify Lo-MacKinlay's test to form a simple multiple variance ratio test and Wright (2000) proposes a nonparametric ranks and signs based variance ratio tests to address the potential limitation of Lo-MacKinlay's conventional variance ratio test.

The introduction of the Euro, a major step of European integration, has drawn interested parties' attention to the Euro exchange rate markets. The Euro was launched on January 1, 1999 as a new and official currency of 11 European countries. After that, the Euro gradually gains its popularity. Currently, the Euro has become the single currency of 15 European Union member countries and the second most widely used international currency in the world. Since the Euro is relatively new, literature regarding the efficiency of the Euro exchange rate markets is relatively scarce and worth developing.

Belaire-Franch and Opong (2005) use the daily nominal exchange rates for 10 currencies relative to the Euro from January 5, 1999 to November 11, 2002 (almost 4 years of data) to investigate the behavior of the Euro exchange rates. Al-Khazali and Koumanakos (2006) use daily nominal Euro exchange rates for 10 Middle Eastern 
and North African (MENA) currencies from January 2000 to December 2004 (5 years of data) to test the RWH of the Euro exchange rates. Both studies indicate that the short historical data available may have some impact on the results.

In this research, I use a longer time period (9-10 years) of historical data and employ three aforementioned variance ratio test methodologies to test the RWH of the Euro/U.S. Dollar exchange rate. The remaining sections of this paper are organized as follows. Section 2 describes data and methodology and empirical results are presented and discussed in section 3 . The conclusion is made in section 4 .

\section{DATA AND METHODOLOGY}

The daily nominal Euro exchange rates (quoted as U.S. dollars per Euro dollar) from January 4, 1999 to July 25, 2008 are collected from International Monetary Fund, Exchange Rates Data. The daily returns are calculated by the first differences of natural logarithm of Euro exchange rates $\left(Y_{t}=\ln P_{t}-\ln P_{t-1}\right)$.

Previous studies (Poshakwale (1996) and Choudhry (2000)) discover day of the week effect phenomenon in the stock markets. Al-Khazali et al. (2007) use weekly (Wednesday) data rather than daily data to test RWH of the stock markets to avoid day of the week effect. To see whether day of the week effect appears at the exchange rate market in this study, I calculate the average return for each weekday and run the dummy variables regression. The regression equation is as follow:

$$
Y_{t}=\alpha+\beta_{1} \text { Tue }+\beta_{2} \text { Wed }+\beta_{3} \text { Thu }+\beta_{4} \text { Fri }+\varepsilon_{t}
$$

where $Y_{t}$ is the daily exchange rate return on day $t . \alpha$ is the intercept. $\beta_{1}, \beta_{2}, \beta_{3}, \beta_{4}$ are coefficients of dummy variables Tue, Wed, Thu, Fri, respectively. $\varepsilon_{t}$ is the error term. Based on equation (1), $\alpha$ would be the average daily exchange rate return for Monday. $\beta_{\mathrm{i}}(\mathrm{i}=1,2,3,4)$ shows the excess return on the specific weekday over Monday. A positive (negative) and significant $\beta_{\mathrm{i}}$ represents that the specific weekday's return is significantly higher (lower) than Monday's return.

\subsection{Conventional Variance Ratio Test By Lo And Mackinlay (1988)}

The variance ratio test of Lo and MacKinlay (1988) is based on the property that the variance of increments of a random walk $X_{t}$ is linear in its data interval. That means, the variance of $\left(X_{t}-X_{t-q}\right)$ is $q$ times the variance of $\left(X_{t}\right.$ $\left.-X_{t-1}\right)$. Therefore, the RWH can be checked by comparing $1 / q$ times the variance of $\left(X_{t}-X_{t-q}\right)$ to the variance of $\left(X_{t}\right.$ $\left.-X_{t-1}\right)$.

Suppose $P_{t}$ is the exchange rate at time $t$ and let a random walk series $X_{t}$ be the natural logarithm of $P_{t}$ [ $X_{t}=\ln P_{t}$ ]. The variance ratio, $\operatorname{VR}(q)$ is defined as:

$V R(q)=\frac{\sigma^{2}(q)}{\sigma^{2}(1)}$

where $\sigma^{2}(q)$ is $1 / q$ times the variance of $\left(X_{t}-X_{t-q}\right)$ and $\sigma^{2}(1)$ is the variance of $\left(X_{t}-X_{t-1}\right)$. The null hypothesis is that $\operatorname{VR}(q)$ is not statistically different from 1 . The equations to calculate $\sigma^{2}(1)$ and $\sigma^{2}(q)$ are as follows.

$$
\sigma^{2}(1)=\frac{1}{n q-1} \sum_{t=1}^{n q}\left(X_{t}-X_{t-1}-\hat{\mu}\right)^{2}
$$


where

$\hat{\mu}=\frac{1}{n q} \sum_{t=1}^{n q}\left(X_{t}-X_{t-1}\right)=\frac{1}{n q}\left(X_{n q}-X_{0}\right)$

and

$\sigma^{2}(q)=\frac{1}{m} \sum_{t=q}^{n q}\left(X_{t}-X_{t-q}-q \hat{\mu}\right)^{2}$

where

$m=q(n q-q+1)\left(1-\frac{q}{n q}\right)$

$X_{n q}$ is the last observation of the data time series. The observation starts at $X_{0}$. There are $n q+1$ observations.

The standard normal test statistic used to test the null hypothesis of random walk under the assumption of homoscedasticity is $Z(q)$, calculated as:

$Z(q)=\frac{(V R(q)-1)}{\sqrt{\theta(q)}} \sim N(0,1)$

where

$\theta(q)=\frac{2(2 q-1)(q-1)}{3 q(n q)}$

The standard normal test statistic used for heteroscedasticity-consistent is $Z^{*}(q)$, calculated as:

$Z^{*}(q)=\frac{(V R(q)-1)}{\sqrt{\theta^{*}(q)}} \sim N(0,1)$

where

$\theta^{*}(q)=\sum_{j=1}^{q-1}\left[\frac{2(q-j)}{q}\right]^{2} \hat{\delta}(j)$

and 


$$
\hat{\delta}(j)=\frac{\sum_{t=j+1}^{n q}\left(X_{t}-X_{t-1}-\hat{\mu}\right)^{2}\left(X_{t-j}-X_{t-j-1}-\hat{\mu}\right)^{2}}{\left[\sum_{t=1}^{n q}\left(X_{t}-X_{t-1}-\hat{\mu}\right)^{2}\right]^{2}}
$$

\subsection{Multiple Variance Ratio Test By Chow And Denning (1993)}

Chow and Denning (1993) point out that failing to control the test size for variance ratio estimates result in large Type I errors. To control the test size and reduce the Type I errors, Chow and Denning (1993) extends LoMacKinlay's (1988) conventional variance ratio test methodology and form a simple multiple variance ratio test, which uses Lo-MacKinlay test statistics as the studentized maximum modulus (SMM) statistics.

Consider a set of variance ratio estimates, $\left\{\mathrm{VR}\left(\mathrm{q}_{\mathrm{i}}\right) \mid \mathrm{i}=1,2,3, \ldots, \mathrm{L}\right\}$, corresponding to a set of pre-defined number of $\operatorname{lag}\left\{\mathrm{q}_{\mathrm{i}} \mid \mathrm{i}=1,2,3, \ldots, \mathrm{L}\right\}$. Under the null hypothesis of random walk, we test a set of subhypotheses, $\mathrm{H}_{0 \mathrm{i}}$ : $\operatorname{VR}\left(\mathrm{q}_{\mathrm{i}}\right)=1$ for $\mathrm{i}=1,2,3, \ldots, \mathrm{L}$. Since any rejection of $\mathrm{H}_{0 \mathrm{i}}$ will lead to the rejection of $\mathrm{RWH}$, let the largest absolute value of the test statistics be

$$
\begin{aligned}
& Z_{1}(q)=\operatorname{Max}_{1 \leq i \leq L}\left|Z\left(q_{i}\right)\right| \\
& Z_{2}(q)=\underset{1 \leq i \leq L}{\operatorname{Max}}\left|Z^{*}\left(q_{i}\right)\right|
\end{aligned}
$$

where $Z\left(q_{i}\right)$ and $Z^{*}\left(q_{i}\right)$ are defined in equation (5a) and (6a). ${ }^{1}$

The decision about whether to reject the null hypothesis can be based on the maximum absolute value of individual variance ratio test statistics. The test statistic follows the SMM distribution with $\mathrm{L}$ and $\mathrm{T}$ (the sample size) degrees of freedom, whose critical values are available in Stoline and Ury (1979). When the sample size T is large, the null hypothesis is rejected at $\alpha$ level of significance if $Z_{I}(q)$ [or $Z_{2}(q)$ ] is greater than the [1- $\left.\left(\alpha^{*} / 2\right)\right]$ th percentile of the standard normal distribution where $\alpha^{*}=1-(1-\alpha)^{1 / \mathrm{L}} \cdot Z_{I}(q)$ and $Z_{2}(q)$ have the same critical values. When $\mathrm{T}$ is large, the $\mathrm{SMM}$ critical values at $\mathrm{L}=4$ and $\alpha$ equal to $10 \%, 5 \%$, and $1 \%$ levels of significance are $2.23,2.49$, and 3.03 , respectively.

\subsection{Non-Parametric Variance Ratio Tests Using Ranks And Signs By Wright (2000)}

Wright (2000) indicates two potential advantages of ranks and signs based tests. First, it is very likely to calculate their exact distributions. The researchers do not need to concern about the size distortions due to no need to appeal to any asymptotic approximation. Second, tests based on ranks and signs may be more powerful than other tests if the data are highly non-normal. Wright (2000) proposes the alternative non-parametric variance ratio tests using ranks and signs of return and demonstrates that they may have better power properties than other variance ratio tests.

\subsubsection{Rank-Based Variance Ratio Tests}

Suppose that $\mathrm{Y}_{\mathrm{t}}$ is a time series of asset returns with a sample size of T. $Y_{t}=X_{t}-X_{t-1}$. Let $\mathrm{r}\left(\mathrm{Y}_{\mathrm{t}}\right)$ be the rank of $Y_{t}$ among $Y_{1}, Y_{2}, \ldots, Y_{T}, r\left(Y_{t}\right)$ is the number from 1 to $T$.

Define 


$$
\begin{aligned}
& r_{1 t}=\frac{\left(r\left(Y_{t}\right)-\frac{T+1}{2}\right)}{\sqrt{\frac{(T-1)(T+1)}{12}}} \\
& r_{2 t}=\Phi^{-1}\left(\frac{r\left(Y_{t}\right)}{T+1}\right)
\end{aligned}
$$

where $\Phi$ is the standard normal cumulative distribution function $\left(\Phi^{-1}\right.$ is the inverse of the standard normal cumulative distribution function).

The series $r_{l t}$ is a simple linear transformation of the ranks, standardized to have sample mean 0 and sample variance 1. The series $r_{2 t}$, known as the inverse normal or van der Waerden scores, has sample mean 0 and sample variance approximately equal to 1 . Wright substitutes $r_{l t}$ and $r_{2 t}$ in place of the return $\left(X_{t}-X_{t-q}\right)$ in the definition of Lo-MacKinlay's variance ratio test statistic (assuming homoscedasticity), $Z(q)$ in equation (5a). The rank-based variance ratio test statistics $R_{I}$ and $R_{2}$ are defined as

$$
\begin{aligned}
& R_{1}=\left(\frac{\frac{1}{T k} \sum_{t=k}^{T}\left(r_{1 t}+r_{1 t-1} \ldots+r_{1 t-k+1}\right)^{2}}{\frac{1}{T} \sum_{t=1}^{T} r_{1 t}^{2}}-1\right) \times\left(\frac{2(2 k-1)(k-1)}{3 k T}\right)^{-1 / 2} \\
& R_{2}=\left(\frac{\frac{1}{T k} \sum_{t=k}^{T}\left(r_{2 t}+r_{2 t-1} \ldots+r_{2 t-k+1}\right)^{2}}{\frac{1}{T} \sum_{t=1}^{T} r_{2 t}^{2}}-1\right) \times\left(\frac{2(2 k-1)(k-1)}{3 k T}\right)^{-1 / 2}
\end{aligned}
$$

Note that $\frac{1}{T} \sum_{t=1}^{T} r_{1 t}^{2}=1$ so that this term may be omitted from the definition of $R_{l}$ in equation (10), whereas

$$
\frac{1}{T} \sum_{t=1}^{T} r_{2 t}^{2} \approx 1
$$

\subsection{2. $\quad$ Sign-Based Variance Ratio Tests}

For any series $Y_{t}$, let $u\left(Y_{t}, q\right)=1\left(Y_{t}>q\right)-0.5$. So, $u\left(Y_{t}, 0\right)$ is $1 / 2$ if $Y_{t}$ is positive and $-1 / 2$ otherwise. Let $s_{t}$ $=2 \mathrm{u}\left(\mathrm{Y}_{\mathrm{t}}, 0\right)=2 \mathrm{u}\left(\varepsilon_{\mathrm{t}}, 0\right)$. Clearly, $\mathrm{s}_{\mathrm{t}}$ is an independently and identically distributed (iid) series with mean 0 and variance 1 . Each $\mathrm{s}_{\mathrm{t}}$ is equal to 1 with probability $1 / 2$ and is equal to -1 otherwise. The signed-based variance ratio test statistic $S_{l}$ is defined as 


$$
S_{1}=\left(\frac{\frac{1}{T k} \sum_{t=k}^{T}\left(s_{t}+s_{t-1} \ldots+s_{t-k+1}\right)^{2}}{\frac{1}{T} \sum_{t=1}^{T} s_{t}^{2}}-1\right) \times\left(\frac{2(2 k-1)(k-1)}{3 k T}\right)^{-1 / 2}
$$

Wright (2000) points out that $S_{2}$ test is expected to have lower power. $S_{2}$ is not computed in this study.

\section{EMPIRICAL RESULTS}

Table 1 illustrates basic statistics for the daily returns of the Euro exchange rate. The daily return ranges from $-2.252 \%$ to $4.2041 \%$, with the mean and median of $0.0118 \%$ and $0.0082 \%$, respectively. If a data series is exactly normally distributed, values of skewness and kurtosis are zero. Values of skewness and kurtosis on Table 1 show that the distribution of Euro exchange rate returns is little positively skewed and somewhat peaked relative to normal.

Table 1: Descriptive Statistics for the Daily Returns of the Euro Exchange Rates

Daily return at day $t\left(Y_{t}\right)$ is computed as $Y_{t}=\ln P_{t}-\ln P_{t-1}$, where $P_{t}$ is the Euro exchange rate at day $t$.

\begin{tabular}{lc}
\hline Mean & $0.0118 \%$ \\
Standard Deviation & $0.6152 \%$ \\
Minimum & $-2.2520 \%$ \\
Maximum & $4.2041 \%$ \\
$1^{\text {st } q u a r t i l e}$ & $-0.3580 \%$ \\
Median & $0.0082 \%$ \\
$3^{\text {rd }}$ quartile & $0.3734 \%$ \\
Skewness & 0.220845 \\
Kurtosis & 1.485572 \\
\hline
\end{tabular}

Panel A in Table 2 shows the average daily return for each weekday. Wednesday has the greatest return and Monday has the lowest return. Panel $\mathrm{B}$ regression analysis indicates that all of $\beta_{\mathrm{i}}(\mathrm{i}=1,2,3,4)$ are not significant. Therefore, day of the week effect does not appear in this case. Daily observations can be used in this study.

Table 2: Average Daily Returns for Each Weekday and Regression Analysis

\begin{tabular}{ccccc}
\hline \multicolumn{5}{c}{ Panel A: Average Daily Returns for Each Weekday } \\
\hline Monday & Tuesday & Wednesday & Thursday & Friday \\
\hline-0.00022337 & 0.00012002 & 0.00039235 & -0.00007620 & 0.00037012 \\
\hline \multicolumn{5}{c}{} \\
\hline $\boldsymbol{\alpha}$ & Panel B: Regression Analysis & $\mathbf{R}_{\mathbf{t}}=\boldsymbol{\alpha}+\boldsymbol{\beta}_{\mathbf{1}} \mathbf{T u e}+\boldsymbol{\beta}_{\mathbf{2}} \mathbf{W e d}+\boldsymbol{\beta}_{\mathbf{3}} \mathbf{T h u}+\boldsymbol{\beta}_{\mathbf{4}}$ Fri $+\boldsymbol{\varepsilon}_{\mathbf{t}}$ & \\
\hline-0.00022337 & $\boldsymbol{\beta}_{\mathbf{1}}$ & $\boldsymbol{\beta}_{\mathbf{2}}$ & $\boldsymbol{\beta}_{\mathbf{3}}$ & $\boldsymbol{\beta}_{\mathbf{4}}$ \\
$(0.4264)$ & 0.00034339 & 0.00061572 & 0.00014717 & 0.00059349 \\
& $(0.3846)$ & $(0.1185)$ & $(0.7093)$ & $(0.1336)$
\end{tabular}

$p$-value is shown in the parenthesis. 


\subsection{Conventional Variance Ratio Test By Lo And Mackinlay (1988)}

Table 3 demonstrates that variance ratio estimates and test statistics of RWH for the entire study period based on the methodology of conventional variance ratio test by Lo and MacKinlay (1988). Results on Table 3 indicate that none of the test statistics for either assuming homoscedasticity or heteroscedasticity-consistent at any number of $\mathrm{q}$ is significant. The null hypothesis that variance ratio is not statistically different from one cannot be rejected. Therefore, the RWH cannot be rejected for the Euro exchange rate.

Table 3: Lo-MacKinlay Variance Ratio Estimates and Test Statistics of RWH for the Entire Period (1/4/1999 7/25/2008)

\begin{tabular}{ccccc}
\hline & \multicolumn{4}{c}{ Number of Lag (q) } \\
\cline { 2 - 4 } & $\mathbf{q = 2}$ & $\mathbf{q}=\mathbf{4}$ & $\mathbf{q}=\mathbf{8}$ & $\mathbf{q}=\mathbf{1 6}$ \\
\hline $\mathbf{V R}(\mathbf{q})$ & 0.9945 & 0.9503 & 0.9505 & 0.9479 \\
$\mathbf{Z}(\mathbf{q})$ & $(-0.2747)$ & $(-1.3135)$ & $(-0.8281)$ & $(-0.5858)$ \\
$\mathbf{Z}^{*}(\mathbf{q})$ & {$[-0.2584]$} & {$[-1.2323]$} & {$[-0.7671]$} & {$[-0.5416]$} \\
\hline
\end{tabular}

The variance ratios for q-day returns, $\operatorname{VR}(\mathrm{q})$, are reported in the first row. $\mathrm{Z}(\mathrm{q})$, variance ratio test statistics assuming homoscedasticity, are reported in the parentheses $(\mathrm{)}) \mathrm{Z}^{*}(\mathrm{q})$, variance ratio test statistics, heteroscedasticity-consistent, are reported in the brackets [ ].

***: Significant at the $1 \%$ level. ${ }^{* *}$ : Significant at the $5 \%$ level. ${ }^{*}$ : Significant at the $10 \%$ level.

Results of the conventional variance ratio test after dividing the entire study period equally into two subperiods are presented on Table 4. Subperiod I ranges from January 4, 1999 to October 15, 2003. Subperiod II starts on October 16, 2003 and ends on July 25, 2008. For each subperiod, none of the test statistics for either assuming homoscedasticity or heteroscedasticity-consistent at any number of $q$ is significant. Again, the RWH cannot be rejected for each subperiod.

Table 4: Lo-MacKinlay Variance Ratio Estimates and Test Statistics of RWH for Two Subperiods

\begin{tabular}{lccccc}
\hline & & \multicolumn{4}{c}{ Number of Lag (q) } \\
\cline { 3 - 5 } Time Period & $\mathbf{q}=\mathbf{2}$ & $\mathbf{q}=\mathbf{4}$ & $\mathbf{q}=\mathbf{8}$ & $\mathbf{q}=\mathbf{1 6}$ \\
\hline Subperiod I: & $\mathbf{V R}(\mathbf{q})$ & 0.9774 & 0.9311 & 0.9564 & 0.9672 \\
$01 / 04 / 1999 \sim 10 / 15 / 2003$ & $\mathbf{Z}(\mathbf{q})$ & $(-0.7889)$ & $(-1.2877)$ & $(-0.5154)$ & $(-0.2604)$ \\
& $\mathbf{Z}^{*}(\mathbf{q})$ & {$[-0.7601]$} & {$[-1.2377]$} & {$[-0.4906]$} & {$[-0.2486]$} \\
Subperiod II: & & & & & 0.9436 \\
$10 / 16 / 2003 \sim 07 / 25 / 2008$ & $\mathbf{V R}(\mathbf{q})$ & 1.0253 & 0.9844 & $(-0.6668)$ & $(-0.5966)$ \\
& $\mathbf{Z}(\mathbf{q})$ & $(0.8830)$ & $(-0.2918)$ & {$[-0.6575]$} & {$[-0.5793]$} \\
\hline
\end{tabular}

The variance ratios for $\mathrm{q}$-day returns, $\mathrm{VR}(\mathrm{q})$, are reported in the first row. $\mathrm{Z}(\mathrm{q})$, variance ratio test statistics assuming homoscedasticity, are reported in the parentheses ()$. Z^{*}(q)$, variance ratio test statistics, heteroscedasticity-consistent, are reported in the brackets [].

***: Significant at the $1 \%$ level. ${ }^{* *}$ : Significant at the $5 \%$ level. ${ }^{*}$ : Significant at the $10 \%$ level.

\subsection{Multiple Variance Ratio Test By Chow And Denning (1993)}

Test statistics based on the methodology of multiple variance ratio test by Chow and Denning (1993) are reported on Table 5. Both of $Z_{1}(q)$ and $Z_{2}(q)$ are not significant for the entire period and any of subperiods. The results fail to reject RWH. 
Table 5: Chow-Denning Variance Ratio Test Statistics of RWH for the Entire Period and Subperiods

\begin{tabular}{|c|c|c|}
\hline Time Period & $\mathbf{Z}_{1}(q)$ & $\mathbf{Z}_{2}(\mathbf{q})$ \\
\hline Entire Period: & & \\
\hline $01 / 04 / 1999 \sim 07 / 25 / 2008$ & 1.3135 & 1.2323 \\
\hline $\begin{array}{l}\text { Subperiod I: } \\
\text { 01/04/1999 10/15/2003 } \\
\text { Subperiod II: }\end{array}$ & 1.2877 & 1.2377 \\
\hline $10 / 16 / 2003 \sim 07 / 25 / 2008$ & 0.8830 & 0.8935 \\
\hline
\end{tabular}

\subsection{Non-Parametric Variance Ratio Tests Using Ranks And Signs By Wright (2000)}

The ranks and signs based variance ratio test statistics based on the methodology by Wright (2000) for the entire period are summarized on Table 6 . The rank-based test results show that $R_{1}$ and $R_{2}$ are insignificant for all numbers of $\mathrm{k}$. The sign-based test results show that $\mathrm{S}_{1}$ is only significant at $5 \%$ level for $\mathrm{k}=4$. For $\mathrm{k}=2,8$, and 16 , $S_{1}$ is not significant. Overall, RWH cannot be rejected by ranks and signs based variance ratio tests except $S_{1}$ for $k$ $=4$.

Table 6: Wright Non-Parametric Variance Ratio Test Statistics of RWH Using Ranks and Signs for the Entire Period

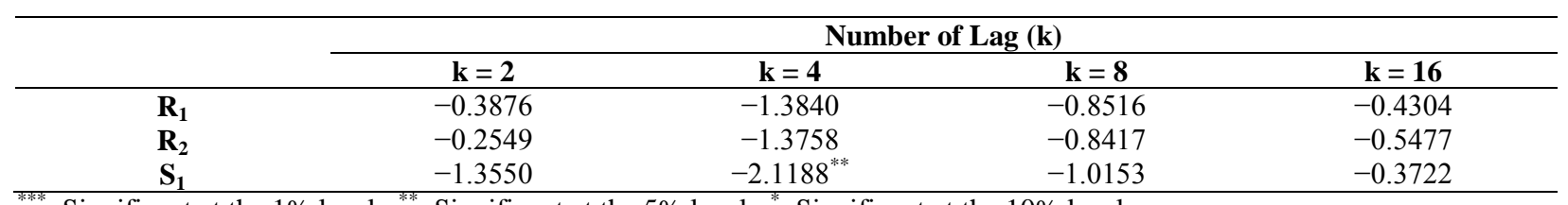

${ }^{* * * *}$ : Significant at the $1 \%$ level. ${ }^{* *}:$ Significant at the 5\% level. ${ }^{*}:$ Significant at the $10 \%$ level.

The results of ranks and signs based variance ratio test statistics for two subperiods are displayed on Table 7. For subperiod $I, R_{1}$ and $S_{1}$ are only significant at $10 \%$ level for $k=4$. For $k=2,8$, and $16, R_{1}, R_{2}$, and $S_{1}$ are all insignificant. All of test statistics are not significant for all numbers of $\mathrm{k}$ in subperiod II. For both subperiods, ranks and signs based variance ratio tests fail to reject RWH except $\mathrm{k}=4$ in subperiod I. According to Tables 6 and 7, the weak-form efficiency of the Euro/U.S. Dollar exchange rate market is supported.

Table 7: Wright Non-Parametric Variance Ratio Test Statistics of RWH Using Ranks and Signs for Two Subperiods

\begin{tabular}{|c|c|c|c|c|c|}
\hline \multirow[b]{2}{*}{ Time Period } & & \multicolumn{4}{|c|}{ Number of Lag (k) } \\
\hline & & $k=2$ & $k=4$ & $k=8$ & $k=16$ \\
\hline Subperiod I: & $\mathbf{R}_{1}$ & -0.8807 & $-1.7162^{*}$ & -0.9119 & -0.3979 \\
\hline $01 / 04 / 1999 \sim 10 / 15 / 2003$ & $\begin{array}{l}\mathbf{R}_{2} \\
\mathbf{S}_{1}\end{array}$ & $\begin{array}{l}-0.8916 \\
-1.2587\end{array}$ & $\begin{array}{l}-1.5498 \\
-1.9572^{*}\end{array}$ & $\begin{array}{l}-0.7416 \\
-0.8365\end{array}$ & $\begin{array}{c}-0.4371 \\
0.0374\end{array}$ \\
\hline $\begin{array}{l}\text { Subperiod II: } \\
10 / 16 / 2003 \sim 07 / 25 / 2008\end{array}$ & $\begin{array}{l}\mathbf{R}_{1} \\
\mathbf{R}_{2} \\
\mathbf{S}_{1}\end{array}$ & $\begin{array}{c}0.1709 \\
0.7219 \\
-0.8293 \\
\end{array}$ & $\begin{array}{l}-0.4605 \\
-0.3529 \\
-1.3603 \\
\end{array}$ & $\begin{array}{l}-0.7352 \\
-0.7373 \\
-0.8700 \\
\end{array}$ & $\begin{array}{l}-0.8219 \\
-0.7935 \\
-1.0443 \\
\end{array}$ \\
\hline
\end{tabular}

${ }^{* * *}:$ Significant at the $1 \%$ level. ${ }^{* *}:$ Significant at the $5 \%$ level. ${ }^{*}:$ Significant at the $10 \%$ level.

\section{CONCLUSION}

The market efficiency is always an important topic to academicians and practitioners. The Euro has become the major international currency after its introduction in January 1999. The growing popularity of the Euro has drawn interested groups' attention on the Euro exchange rate markets. This study uses the daily nominal 
Euro/U.S. Dollar exchange rate data (quoted as U.S. dollars per Euro dollar) from January 4, 1999 to July 25, 2008 and employs three variance ratio tests: Lo-MacKinlay's (1988) conventional variance ratio test, Chow-Denning's (1993) simple multiple variance ratio test, and Wright's (2000) non-parametric ranks and signs based variance ratio tests to examine the random walk of the Euro/U.S. Dollar exchange rate market. Results of these three variance ratio tests consistently indicate that the null hypothesis of random walk cannot be rejected. Therefore, the Euro/U.S. Dollar exchange rate market is considered weak-form efficient.

\section{AUTHOR INFORMATION}

Jeng-Hong Chen is currently an assistant professor of finance at College of Business, Albany State University. Dr. Chen mainly teaches corporate finance in undergraduate and graduate school. In addition, he also had the experience of teaching business statistics and principles of microeconomics. In terms of the ways of course delivery, he has face-to-face, online, and IP video conferencing class teaching experience. Dr. Chen's research interest includes fixed income securities, market microstructure, and international finance. He had papers published in finance and economics journals.

\section{REFERENCES}

1. Al-Khazali, O. M., D. K. Ding, and C. S. Pyun, 2007, A New Variance Ratio Test of Random Walk in Emerging Markets: A Revisit, The Financial Review 42, 303-317.

2. Al-Khazali, O. M. and E. P. Koumanakos, 2006, Empirical Testing of Random Walk of Euro Exchange Rates: Evidence From The Emerging Markets, Journal of Business and Economic Research 4, 65-74.

3. Belaire-Franch, J. and K. K, Opong, 2005, Some Evidence of Random Walk Behavior of Euro Exchange Rates Using Ranks and Signs, Journal of Banking and Finance 29, 1631-1643.

4. Choudhry, T., 2000, Day of the Week Effect in Emerging Asian Stock Markets: Evidence from the GARCH model, Applied Financial Economics 10, 235-242.

5. Chow, K. V. and K. C. Denning, 1993, A Simple Multiple Variance Ratio Test, Journal of Econometrics $58,385-401$.

6. Huang, B., 1995, Do Asian Stock Market Prices Follow Random Walks? Evidence from the Variance Ratio Test, Applied Financial Economics 5, 251-256.

7. Islam, A. and M. Khaled, 2005, Tests of Weak-Form Efficiency of the Dhaka Stock Exchange, Journal of Business Finance and Accounting 32, 1613-1624.

8. Liu, C. Y. and J. He, 1991, A Variance-Ratio Test of Random Walks in Foreign Exchange Rates, The Journal of Finance 46, 773-785.

9. Lo, A. W. and A. C. MacKinlay, 1988, Stock Market Prices Do Not Follow Random Walks: Evidence from a Simple Specification Test, The Review of Financial Study 1, 41-66.

10. Poshakwale, S., 1996, Evidence on Weak Form Efficiency and Day of the Week Effect in the Indian Stock Market, Finance India 10, 605-616.

11. Stoline, M. R. and H. K. Ury, 1979, Tables of the Studentized Maximum Modulus Distribution and an Application to Multiple Comparisons among Means, Technometrics 21, 87-93.

12. Wright, J. H., 2000, Alternative Variance-Ratio Tests Using Ranks and Signs, Journal of Business and Economic Statistics 18, 1-9.

\section{Endnote}

1 In this research, $q=2,4,8,16$ are used to calculate variance ratio estimates and test statistics. Therefore, $\left\{q_{i} \mid i=1,2,3\right.$, and 4) such that $\mathrm{q}_{1}=2, \mathrm{q}_{2}=4, \mathrm{q}_{3}=8$, and $\mathrm{q}_{4}=16$. 
NOTES 